\title{
The minimum price required by investors in IPOs
}

\author{
Ahmed Jeribi $^{\mathrm{a}^{*}}$ and Anis Jarboui ${ }^{\mathrm{b}}$
}

${ }^{a}$ Department of Finance and Accounting, Faculty of Economics and Management of Sfax (FSEGS), Tunisia ${ }^{b}$ Department of Finance and Accounting, Higher Institute of Business Administration of Sfax (ISAAS), Tunisia

\section{H R O N I C L E}

Article history:

Received March 15, 2014

Accepted September 6, 2014

Available online

September 92014

Keywords:

Initial public offering (IPO)

Tunisia

Minimum price required by

investors

\section{Introduction}

Much evidence suggests that IPO shares are systematically priced at a discount. Underpricing has been greatly documented in several studies in the Tunisian context (Smith, 1986; Rock, 1986; Roosenboom, 2012; Jeribi \& Jarboui, 2014). For example, Gana and El Ammari (2008), Ben Slama et al. (2011) and Kanoun and Taktak (2013) among others provide evidence suggesting that the existence of an average underpricing (initial returns) of up to $25 \%$ has been a persistent feature of the Tunisian new issues market. However, such underpricing is lower than the one in the Asian markets (Agarwal et al., 2008; Marisetty \& Subrahmanyam, 2010; Bubna \& Prabhala, 2011). There are several studies that purport to explain underpricing, have appeared in literature. Ibbotson (1975) argues that issuers undervalue their shares in order to "leave a good taste in investors' mouths". Rock (1986) explains underpricing as the direct result of the winner's curse problem facing uninformed investors when they submit their purchase orders for new issues. He argues that an uninformed investor would be * Corresponding author.

E-mail address: ahmedjeribi07@yahoo.fr (A. Jeribi) 
encouraged to participate in IPOs only if shares are offered at discounts from their expected postlisting prices. Therefore, firms are forced to undervalue their shares in order to compensate uninformed investors for this adverse selection. The excess returns earned from undervalued shares should be sufficient to compensate informed investors for the costs of acquiring information. Koh and Walter (1989) test and confirm the empirical implications of Rock (1986) for 66 new issues on the Singapore Stock Exchange. They find that the uninformed investors' returns are not statically different from the risk-free rate. They also find that rationing is the major reason for IPO excess return. It is shown to be applied much stringently in underpriced than in overpriced issues. Koh and Walter (1989) assume that purchasing IPO shares involves an opportunity interest cost of $2 \%$ above prime, calculated for the period for which funds are tied up. In Singapore Stock Exchange, the allocation system for small investors is more beneficial than the one for large investors. In contrast to the model of Rock (1986), Levis (1990) finds that the settlement mechanism of the British institutional framework imposes an additional cost on both uninformed and informed investors. This additional cost is the interest rate charges. He also finds that, when the interest rate costs and the winner's curse problem are taken into consideration, the first day net returns are, on average, lower than the level of underpricing. Keloharju (1993) also test Rock's (1986) winner's curse hypothesis for 88 IPO firms listed on the Helsinki Stock Exchange. He finds that if offerings are oversubscribed, the proportional allocations depend on the order size. The number of allocated shares is generally a nondecreasing function of application size. However, the Finnish rules are designed so that they favor small investors. He calculates the initial excess returns. He adjusts initial returns by taking into consideration risk-free interest rate and transaction cost. He finds that investors who place large orders are given less proportional allocations than those who place small orders. As a consequence, small orders yield significantly positive returns, whereas large application sizes yield significantly negative returns.

Lee et al. (1996) divide the period between the official registration of the prospectus and the beginning of exchange trading into three sub-periods. First, there is a period between the official registration of the prospectus and the opening of the issue to subscribers. Second, there is a subscription period (between the opening of the issue and the closing). Finally, there is a period between the issue closing and the beginning of exchange trading. They notice that the first and the third period are largely standardized and administrative. They assume that the issues with long delays have difficulty to attract interest from informed investors who are not confronted to the winner's curse faced by the uninformed. Using a sample of 266 Australian industrial IPOs between 1976 and 1989, they show that underpricing is negatively related to the time to listing (the time between the prospectus registration and the exchange listing). Chowdhry and Sherman (1996) observe larger underpricing, larger oversubscription levels, a larger probability of observing extremely high levels of subscription compared to issues in which the offer price is set only few days prior to the beginning of the offer. Mok and Hui (1998) find a positive relationship between the time gap between the offering and the listing and underpricing. However, they find a negative relationship between the time gap between offering and listing and underpricing for the sub-sample of 26 overpriced IPOs. They interpret this result with caution. It means that the longer the time gap between offering and listing is, the higher the ex ante uncertainty and the lower the overpricing are. How and Yeo (2000) find that the subscription period is set in light of the investor's demand. The underwriter is likely to set a longer subscription period for IPO shares that are expected to have a low subscription rate. A lower subscription period may decrease the probability of full subscription. Cheng et al. (2005) argue that the length of the period from the IPO application to the listing date indicates the quality of the IPO. They predict a positive relationship between the length of the investment period and the probability of having a poor coordination of the operation and a negative relationship between the length of the investment period and the quality of IPO. They find that the investment period and the market adjusted IPO opening returns are negatively and significantly associated. However, Low and Yong's (2011) interpretation of this period is different from that of Cheng et al. (2005). They assume that the 
number of days from the subscription period to the listing day (the investment period) is viewed as a good proxy for the opportunity cost of funds.

Sherman and Titman (2002) find that, when information for investors is costly to obtain, IPO shares must be underpriced sufficiently in order to offset this problem and induce all investors to collect information. They show that the cost of attracting more investors is that the issue might need to be more underpriced. They also show that when there is little requirement for accurate pricing, few investors will be invited to participate in the IPO, little underpricing will be required, and the expected gain from underpricing will exactly compensate the cost of information which is paid by investors. However, when there is a strong requirement for accurate pricing, the informed investors will be more invited to participate in the offering and will earn rents. Therefore, the expected gain from underpricing will exceed the information costs. These authors also find that, when pricing accuracy is important, the number of investors participating during the subscription period is larger, and underpricing is greater. Hence, investors can earn economic rents. Berger and Turtle (2012) find that investors who are concerned with the credibility of information measures may require additional compensation in order to entice them to keep shares with less transparent information.

The mechanism of allocating IPO shares in Tunisia is similar to those employed in the Asian markets, including Hong Kong, China and Singapore. Tunisian firms allocate their shares through a quotas procedure. Shares are allocated into two major categories: institutional and non-institutional investors. Indeed, the Tunisian firms fix their desired ownership structure. After the announcement of the subscription result, the non-institutional investors are equally served and the institutional investors will be served with a pro rata rationing system if there is an excess demand. The institutional framework of the Tunisian financial market imposes costs resulting from the obligation to pay cash for the amount concerning the shares requested (taxes and fees included) by the investor. Likewise, the difference between the amount paid during the subscription period and the amount due will be refunded. Indeed, investors suffer from shortfall as a result from the blocking of the amount of money that is initially placed until the date of the potential sale. In order to be informed, the investor spends money in order to collect the necessary information. Furthermore, he pays transaction costs when selling his shares. Ben Slama et al. (2011), Kanoun and Taktak (2013) have investigated the underpicing level on the Tunisian market. Jeribi and Jarboui (2014) have studied the deliberate price discount level in the same market. However, these authors and others, who treated the IPO issue, have neglected the shortfall resulting from the blocking of the amount of money, information costs and transaction costs. In this study, we consider the case of a non-institutional investor and an institutional investor who transmit a purchase order of a certain number of IPO shares at the offer price during the subscription period. We have determined the minimum price required by an investor which allows him to cover his initial investment, information costs, transaction costs and offset his shortfall. It is the price above which the investor makes a profit. Likewise, the investor might have a positive return, but the closing price does not allow him to cover his initial investment, information costs and transaction costs and offset his shortfall. There is not an excess return. Furthermore, we have identified the determinant of the minimum price required by investors (non-institutional and institutional). We also have identified the meaning of the relation between the minimum price required and its determinants. We find that the number of days between the closing date of the subscription period and the day following the announcement of the subscription result and the number of days between the announcement of the subscription result and the first listing day are good proxies for the opportunity cost of funds as found by Low and Yong (2011). This opportunity cost of funds increase the minimum price required by investors. Our interpretation is different from those of Lee et al. (1996), Mok and Hui (1998) and Cheng et al. (2005). We also expect that the initial return of an IPO share on the Tunisian market is explained by: the subscription ratio of institutional investors, the expected rate of return by investors, the gap between the closing date of the subscription period and the day following the announcement of the subscription result, the gap between the announcement of the subscription result and the first listing day, the number of trading 
days, the cost of information and the transaction costs. However, it is negatively related to: the discount level, the number of shares allocated to a non-institutional investor and the number of offered shares which are allocated to non-institutional investors.

This paper can have many important contributions to literature, the Tunisian stock market intermediary and Tunisian investors. The first contribution is the minimum price required by investors (non-institutional and institutional). This price can help investors to streamline their investment decisions. It also provides a new financial advisory product. The second contribution is to provide a new model to test what explains the IPO underpricing in the Tunisian stock market.

The remainder of this paper is organized as follows: Section 2 presents the model and the implications; Section 3 is the conclusion.

\section{Model}

Jiang and Li (2013) show that IPOs have a "Dual Tranche system" with placing tranche for institutional investors and public tranche for retail investors in the Hong Kong market. This system is similar to the one in Tunisia. The number of shares offered to the public is allocated through a quotas procedure. Indeed, owners fix their desired ownership structure. IPO shares are allocated into two major categories: institutional and non-institutional investors.

$O S=O S^{I}+O S^{N I}$

OS : The total number of offered shares,

OS ${ }^{I}$ : The number of offered shares, which are allocated to institutional investors,

$O S^{N I}$ : The number of offered shares, which are allocated to non-institutional investors.

Welch (1989) and Allen and Faulhaber (1989) argue that firms can signal their quality (good or bad) by underpricing and only good firms can afford to dissipate wealth by underpricing their initial issue. Arthurs et al. (2009) show that IPOs are typically surrounded by significant uncertainty. The higher uncertainty related to the IPO firms tends to dictate a higher discount level in order to induce investors to participate. In order to determine the fair value estimate of the IPO firms, Tunisian underwriters often employ net accounting assets, discounted cash flow, multiple valuation and goodwill. In order to set the offer price (subscription price), Tunisian underwriters voluntarily discount the fair value estimate (Jeribi \& Jarboui, 2014; Jeribi et al., 2014).

$O P=F V \times(1-D)$

$O P$ : The offer price,

$F V$ : The fair value estimate,

$D$ : The discount level.

During the subscription period, Tunisian investors (institutional and non-institutional) transmit their purchase orders at the offering price. They are required to make advance payment via bank draft for the IPO shares that they want to apply. The total requested number of IPO shares will be the sum of those requested by both institutional and non-institutional investors.

$R Q=R Q^{I}+R Q^{N I}$

$R Q$ : The total number of IPO requested shares,

$R Q^{I}$ : The number of IPO shares requested by institutional investors,

$R Q^{N I}$ : The number of IPO shares requested by non-institutional investors. 
The main concern of all investors is to maximize their wealth. Therefore, each investor who participates in IPO by sending a purchasing order during the subscription period anticipates a procured value added. Every investor wants to benefit from IPO premium, which is the discount. Indeed, he anticipates a high growth of the share price in the secondary market in order to repay his incurred costs and benefit from value created.

\subsection{The minimum price required by a non-institutional investor}

If we consider the case of a non-institutional investor who transmits a purchase order of certain number of IPO shares at the offer price during the subscription period, the amount of money, which is initially placed (the value of the purchase order), is determined as follows.

$X^{N I I}=R Q^{N I I} \times O P$

$X^{N I I}$ : The value of the purchase order,

$R Q^{N I I}$ : The number of shares requested by a non-institutional investor.

Rock (1986) finds that firms undervalue their IPOs in order to compensate uninformed investors for the adverse selection problem. Unlike Rock's model, Levis (1990) find that the institutional framework of the UK imposes an additional cost (interest rate charges) on both informed and uninformed investors. In Finland, Keloharju (1993) finds that investors usually need not pay for IPO shares when they place their orders. The institutional framework of the Tunisian financial market imposes costs resulting from the obligation to pay cash for the amount concerning the requested shares (taxes and fees included) on the investor. The shortfall resulting from the blocking of the amount of money that is initially placed until the date of the potential sale is expressed as follows:

$S_{n}^{N I I}=X^{N I I} \times\left[\left(1+r_{N I I}\right)^{\frac{N 1}{365}}-1\right] \times\left(1+r_{N I I}\right)^{\frac{N 2+n-1}{365}}$

$S_{n}^{N I I}$ : The shortfall resulting from the blocking of the amount of money $X^{\text {NII }}$ that is initially placed until the date of the potential sale,

$r_{N I I}:$ The expected rate of return by a non-institutional investor,

$N 1$ : The number of days between the transmission date of the purchase order and the day following the announcement of the subscription result,

$N 2$ : The number of days between the announcement of the subscription result and the first listing day,

$\mathrm{n}$ : The number of trading days.

Rock (1986) classified investors into two categories: uninformed and informed investors. IPO firms should undervalue their shares in order to attract uninformed investors. In order to ensure that the uninformed investors purchase the new issue and ensure the successful operation of the issue, an IPO firm must undervalue its shares by practicing a discount. Sherman and Titman (2002) find that when information is costly, the level of underpricing is determined by the desire of investors for information. The expected underpricing level compensates for investors the costs of acquiring information. They also find that IPO shares must be underpriced sufficiently to offset the moral hazard problem and to induce all investors to collect information.

A rational investor who chooses to participate in an IPO should acquire some related information in order to rationalize his choice. In order to be informed, the investor spends money to collect necessary information. The information costs are expressed as follows:

$I C^{N I I}=I C_{N I I}^{u} \times R Q^{N I I} \times O P$

$I C^{N I I}$ : The total cost of information spent by a non-institutional investor,

$I C_{N I I}^{u}:$ The cost of information spent by a non-institutional investor in percentage. 
At the announcement of the IPO result, two scenarios present themselves according to the expectations of non-institutional investors. The first scenario is as follows: the non-institutional investors are equally served if there is an excess demand. Indeed, they expect that the IPO shares are underpriced. The second is as follows: If the non-institutional investors expect that the IPO shares are overpriced, each investor who transmits a purchase order will have the requested shares.

The first scenario: $R Q^{N I} \geq O S^{N I}$

The non-institutional investors are equally served. Each investor will have a number of shares equal to:

$A Q^{N I I 1}=\frac{O S^{N I}}{N N I I}$

$A Q^{N I 1}$ : The number of shares allocated to a non-institutional investor according to the first scenario, NNII : The number of non-institutional investors participating during the subscription period.

After the announcement of the IPO result and the satisfaction of investors, the difference between the amount paid during the subscription period and the amount due will be refunded. In this case, the investor has only the following amount on the day of announcement of the IPO result:

$X A^{N I I 1}=A Q^{N I I 1} \times O P$

$X A^{\text {NII1 }}$ : The blocked amount at the disposal of the investor after the allocation of shares according to the first scenario.

This amount will be at the disposal of the investor until the date when he decides to sell his shares. The minimum wealth of the investor at date $\mathrm{n}\left(M W_{n}^{N I I 1}\right)$ which compensates his initial costs is expressed as follows:

$M W_{n}^{N I I 1}=A Q^{N I I 1} \times M P_{n}^{N I I 1}$

$M P_{n}^{N I I 1}$ : The minimum price required by the investor at date $\mathrm{n}$ according to the first scenario.

The investor's expenditures are: the blocked amount $X A^{N I I 1}$, the shortfall incurred through the placing of the blocked amount, the cost of information and transaction costs related to the sale of IPO shares. The shortfall incurred through the placing of the blocked amount $B^{N I 1}$ is as follows:

$B_{n}^{N I I 1}=X A^{N I I 1} \times\left[\left(1+r_{N I I}\right)^{\frac{N 2+n}{365}}-1\right]$

At the date $\mathrm{n}$, the information costs are given by the following expression:

$I C_{n}^{N I I}=I C^{N I I} \times\left(1+r_{N I I}\right)^{\frac{N 1+N 2+n-1}{365}}$

The transaction costs related to the sale of IPO shares are as follows:

$T C^{N I I}=T C_{N I I}^{u} \times A Q^{N I I} \times M P_{n}^{N I I}$

$T C^{N I I}$ : The total transaction costs for the non-institutional investor,

$T C_{N I I}^{u}$ : The transaction costs for the non-institutional investor in percentage.

By equalizing the expected revenue with the expected expenditure, we can identify the following relationship:

$M W_{n}^{N I I 1}=S_{n}^{N I I}+X A^{N I 11}+B_{n}^{N I I 1}+I C_{n}^{N I I}+T C^{N I I}$ 


$$
M P_{n}^{N I I 1}=\frac{O P}{\left(1-T C_{N I I}^{u}\right)} \times\left[\begin{array}{l}
\frac{R Q^{N I I}}{A Q^{N I I}} \times\left[\left(1+r_{N I I}\right)^{\frac{N 1}{365}}-1\right] \times\left(1+r_{N I I}\right)^{\frac{N 2+n-1}{365}}+\left(1+r_{N I I}\right)^{\frac{N 2+n}{365}} \\
+\frac{R Q^{N I I}}{A Q^{N I I}} \times I C_{N I I}^{u} \times\left(1+r_{N I I}\right)^{\frac{N 1+N 2+n-1}{365}}
\end{array}\right]
$$

In order to study the relationship between the minimum price required by a non-institutional investor and its determinants, we determine the derivatives of the function of the minimum required price. Table 1 presents the determinants of the minimum price required by a non-institutional investor and the sense (positive or negative) of possible relationships (see Appendix 1).

\section{Table 1}

The determinants of the minimum price required by a non-institutional investor

\begin{tabular}{lc}
\hline The determinants & Expected sign \\
\hline The offer price, & + \\
The discount level, & + \\
The number of shares requested by a non-institutional investor, & + \\
The number of shares allocated to a non-institutional investor, & - \\
The number of offered shares which are allocated to non-institutional investors, & + \\
The number of non-institutional investors participating during the subscription period, & + \\
The expected rate of return by a non-institutional investor, & + \\
The number of days between the transmission date of the purchase order and the day following the & + \\
The number of days between the announcement of the subscription result and the first listing day, & + \\
The number of trading days, & + \\
The cost of information spent by a non-institutional investor in percentage, & + \\
\hline
\end{tabular}

We find that the minimum price required by a non-institutional investor is negatively related to the discount level. The greater the discount level is, the quicker the investor can recover his funds provided that there is a favorable variation in the share price. The deliberate price discount is the counterparty provided by the IPO firm so that the investor can recover his funds and the shortfall resulting from the blocking of funds and the information costs. We also find that the minimum price required by a non-institutional investor is positively related to the number of shares requested during the subscription period. The more optimistic the expectations of the investor are, the greater the number of requested shares is, the higher the difference between the number of requested shares and the number of allocated shares is, the higher the shortfall resulting from the blocking of funds is, and consequently the higher the minimum required price is. The minimum price required by a noninstitutional investor is negatively related to the number of allocated shares. The lower the number of allocated shares is, the higher the shortfall resulting from the blocking of funds is, and consequently the higher the minimum required price is. This result is consistent with that of Keloharju (1993). The number of shares allocated to a non-institutional investor is only the ratio between the number of the offered shares which are allocated to non-institutional investors and the number of non-institutional investors participating during the subscription period. By replacing the number of allocated shares by its expression, we also find that the minimum price required is positively related to the number of participating investors. This result is consistent with that of Brennan and Frank (1997), Zheng and Li (2008), Degeorge et al. (2010), Ahmad-Zaluki (2011) and Neupane and Poshakwale (2012). It is also negatively related to the number of offered shares which are allocated to institutional investors. By multiplying the offer price by the number of offered shares, we have the issue size concerning noninstitutional investors. This result is consistent with that of Beatty and Ritter (1986) and others ${ }^{1}$. Beatty and Ritter (1986) argue that small issue size is subject to more ex ante uncertainty. However,

${ }^{1}$ Michaely \& Shaw (1994), Mok \& Hui (1998), Amihud et al. (2003), Agarwal et al (2008), Marisetty \& Subrahmanyam (2010) and Agathee et al. (2012). 
we argue that small issue size implies a lower allocated quantity, and consequently the higher the minimum price required and the shortfall resulting from the blocking of funds are. The minimum price required by a non-institutional investor is also positively related to the number of days between the transmission date of the purchase order and the day following the announcement of the subscription result. This period can be divided into two sub-periods: a first sub-period that lies between the transmission date of the purchase order and the closing date of the subscription period and a second sub-period that lies between the closing date of the subscription period and the day following the announcement of the subscription result. In our study, we adopt Low and Yong's (2011) interpretation of the second sup-period. To minimize this period and therefore his shortfall, the investor may act in the first sub-period by subscribing to the last day of the subscription period. In contrast, the second sub-period is an exogenous data for investors. We also find that the higher the number of days between the announcement of the subscription result and the first listing day, the higher the shortfall resulting from the blocking of funds is, and consequently the higher the minimum required price is. This result is consistent with that of Koh and Walter (1989), Keloharju (1993), Cheng et al. (2005) and Low and Yong (2011). The minimum price required by a non-institutional investor is also positively related to the cost of information and the transaction costs.

The second scenario: $R Q^{N I}<O S^{N I}$

If the non-institutional investors expect that the IPO shares are overpriced, each investor who transmits a purchase order will have the number of requested shares. We take the example of a noninstitutional investor who participates in an overpriced IPO and transmits a purchase order of a certain number of shares at the offer price during subscription period. The shortfall resulting from the blocking of the amount of money that is initially placed $X^{\text {NII }}$ until the date of the potential sale $E_{n}^{N I I 2}$ is expressed as follows:

$E_{n}^{N I I 2}=X^{N I I} \times\left[\left(1+r_{N I I}\right)^{\frac{N 1+N 2+n-1}{365}}-1\right]$

The minimum wealth of the investor at date $\mathrm{n}\left(M W_{n}^{N I 2}\right)$ which compensates his initial costs is expressed as follows:

$M W_{n}^{N I I 2}=R Q^{N I I} \times M P_{n}^{N I I 2}$

$M P_{n}^{N I I 2}$ : The minimum price required by the investor at date $\mathrm{n}$ according to the second scenario.

By equalizing the expected revenue for a non-institutional investor who participates in an overpriced IPO with his expected expenditure, we can identify the following relationship:

$$
\begin{aligned}
& M W_{n}^{N I I 2}=X^{N I I}+E_{n}^{N I I 2}+I C_{n}^{N I I}+T C^{N I I} \\
& M P_{n}^{N I I 2}=\frac{O P \times\left(1+r_{N I I}\right)^{\frac{N 1+N 2+n-1}{365}} \times\left(1+I C_{N I I}^{u}\right)}{\left(1-T C_{N I I}^{u}\right)}
\end{aligned}
$$

If the non-institutional investors expect the issue to be overpriced, the minimum price required by the investor at date $\mathrm{n}$ is a capitalization of the offer price increased by the information costs and the transaction costs at the expected rate of return during the period that lies between the transmission date of the purchase order and the date of potential the sale.

\subsection{The minimum price required by a non-institutional investor}

If we consider the case of an institutional investor who transmits a purchase order of certain number of IPO shares at the offer price during the subscription period, the amount of money initially placed (the value of the purchase order) is determined as follows:

$X^{I I}=R Q^{I I} \times O P$ 
$X^{I I}$ : The value of the purchase order,

$R Q^{I I}$ : The number of shares requested by an institutional investor.

The shortfall resulting from the blocking of the amount of money initially placed until the date of the potential sale is expressed as follows:

$S_{n}^{I I}=X^{I I} \times\left[\left(1+r_{I I}\right)^{\frac{N 1}{365}}-1\right] \times\left(1+r_{I I}\right)^{\frac{N 2+n-1}{365}}$

$S_{n}^{I I}$ : The shortfall resulting from the blocking of the amount of money $X^{I I}$ initially placed until the date of the potential sale,

$r_{I I}:$ The expected rate of return by an institutional investor.

The information costs for an institutional investor are expressed as follows:

$I C^{I I}=I C_{I I}^{u} \times R Q^{I I} \times O P$

$I C^{I I}$ : The total cost of information spent by an institutional investor,

$I C_{I I}^{u}$ : The cost of information spent by an institutional investor in percentage.

At date $\mathrm{n}$, the information costs are given by the following expression:

$I C_{n}^{I I}=I C^{I I} \times\left(1+r_{I I}\right)^{\frac{N 1+N 2+n-1}{365}}$

At the announcement of the IPO result, there are two scenarios according to the expectations of institutional investors. The first scenario is when the institutional investors are served with a pro rata rationing system if there is an excess demand. The second is when the institutional investors expect IPO shares to be overpriced; each investor who transmits a purchase order will have the number of requested shares.

The first scenario: $R Q^{I} \geq O S^{I}$

Each institutional investor will have a number of shares equal to:

$A Q^{I I 1}=\frac{R Q^{I I}}{S R^{I I 1}}$

$S R^{I I}$ : The subscription ratio of institutional investors.

$S R^{I I 1}=\frac{R Q^{I}}{O S^{I}}$

According to the first scenario, the investor has only the following amount $X A^{I I 1}$ on the day of announcement of the IPO result:

$X A^{I I 1}=A Q^{I I 1} \times O P$

$X A^{I I 1}$ : The amount blocked by the institutional investor after the allocation of IPO shares according to the first scenario.

At date n, the shortfall incurred through the placing of the blocked amount $B^{I I 1}$ is as follows:

$B_{n}^{I I 1}=X A^{I I 1} \times\left[\left(1+r_{I I}\right)^{\frac{N 2+n}{365}}-1\right]$

The minimum wealth of the institutional investor at date $\mathrm{n}\left(M W_{n}^{I I 1}\right)$ which compensates his initial costs is as follows:

$M W_{n}^{I I 1}=A Q^{I I 1} \times M P_{n}^{I I 1}$

$M P_{n}^{I I 1}$ : The minimum price required by the institutional investor at date $\mathrm{n}$ according to the first scenario. 
The transaction costs related to the sale of IPO shares are as follows:

$T C^{I I}=T C_{I I}^{u} \times A Q^{I I 1} \times M P_{n}^{I I 1}$

$T C^{N I I}$ : The total transaction costs for the institutional investor,

$T C_{N I I}^{u}$ : The transaction costs for the institutional investor in percentage.

By equalizing the expected revenue with the expected expenditure, we can identify the following relationship:

$$
\begin{aligned}
& M W_{n}^{I I 1}=S_{n}^{I I}+X A^{I I 1}+B_{n}^{I I 1}+I C_{n}^{I I}+T C^{I I} \\
& M P_{n}^{I I 1}=\frac{O P}{\left(1-T C_{I I}^{u}\right)} \times\left[\begin{array}{l}
S R^{I I 1} \times\left[\left(1+r_{I I}\right)^{\frac{N 1}{365}}-1\right] \times\left(1+r_{I I}\right)^{\frac{N 2+n-1}{365}}+\left(1+r_{I I}\right)^{\frac{N 2+n}{365}} \\
+S R^{I I 1} \times I C_{I I}^{u} \times\left(1+r_{I I}\right)^{\frac{N 1+N 2+n-1}{365}}
\end{array}\right]
\end{aligned}
$$

\section{Table 2}

The determinants of the minimum price required by an institutional investor

\begin{tabular}{lc}
\hline The determinants & Expected sign \\
\hline The offer price, & + \\
The discount level, & + \\
The subscription ratio of institutional investors, & + \\
The expected rate of return by an institutional investor, & + \\
The number of days between the transmission date of the purchase order and the day following the & + \\
The number of days between the announcement of the subscription result and the first listing day, & + \\
The number of trading days, & + \\
The cost of information spent by an institutional investor in percentage, & + \\
\hline
\end{tabular}

From table 2, we find that the minimum price required by an institutional investor is positively related to the subscription ratio of institutional investors. This result is consistent with that of Keloharju (1993). Likewise, Agarwal et al. (2008), Marisetty and Subrahmanyam (2010) and Bubna and Prabhala (2011) find a positive relationship between underpricing and the total subscription ratio. Ben Slama et al. (2011) find a positive relationship between underpricing and the total subscription ratio for 34 Tunisian IPOs from the period 1992-2008. We also find that the minimum price required by an institutional investor is positively related to: the offer price, the expected rate of return by an institutional investor, the number of days between the transmission date of the purchase order and the day following the announcement of the subscription result, the number of days between the announcement of the subscription result and the first listing day, the number of trading days, the cost of information in percentage and the transaction costs in percentage. However, it is negatively related to the discount level. These results are similar to those found when studying the determinants of the minimum price required by a non-institutional investor.

\section{The second scenario: $R Q^{I}<O S^{I}$}

In order to determine the minimum price required by the institutional investor at date $\mathrm{n}$ according to the second scenario $M P_{n}^{I I 2}$, we adopt the same step as for the one required by the non-institutional investor at date $\mathrm{n}$ according to the second scenario.

$$
M P_{n}^{I I 2}=\frac{O P \times\left(1+r_{I I}\right)^{\frac{N 1+N 2+n-1}{365}} \times\left(1+I C_{I I}^{u}\right)}{\left(1-T C_{I I}^{u}\right)}
$$

If institutional investors expect the issue to be overpriced, the minimum price required by the investor at date $\mathrm{n}$ is a capitalization of the offer price increased by the information and the transaction costs at the expected rate of return during the period between the transmission date of the purchase order and that of the potential sale. It is the same as for a non-institutional investor. 


\section{Conclusion}

In this study, we tried to find out the minimum price required by both a non-institutional and an institutional investor who transmit a purchase order of certain number of IPO shares at the offer price during the subscription period. This is the price that enables investors to recover their initial investment and offset their shortfall. If the share price exceeds the minimum required price, the investor makes a profit. However, if the share price is below the minimum required price, the investor can retain shares if he expects a favorable trend of the share price. If the investor believes an unfavorable change of the share price and has short term investment horizon, he sells his shares in order to minimize his shortfall. Likewise, the investor might have a positive return on the first trading day, but the first trading day closing price does not enable him to recover his initial investment, information costs and transaction costs and offset his shortfall. Indeed, there is not an initial excess return (Keloharju, 1993). After having identified the determinant of the minimum price required by a non-institutional investor and an institutional investor, we expect that the initial return of an IPO share is explained by: the offer price, the number of non-institutional investors participating during the subscription period, the expected rate of return by investors, the number of days between the closing date of the subscription period and the day following the announcement of the subscription result, the number of days between the announcement of the subscription result and the first listing day, the number of trading days, the cost of information, the transaction costs and the subscription ratio of institutional investors. However, it is negatively related to: the discount level, the allocated quantity for a non-institutional investor and the number of offered shares which are allocated to noninstitutional investors

\section{Appendices}

\section{Appendix 1}

The determinants of the minimum price required by a non-institutional investor

$$
\begin{aligned}
& \frac{d M P_{n}^{N I I} 1}{d O P}=\frac{1}{\left(1-T C_{N I I}^{u}\right)} \times\left[\begin{array}{l}
\frac{R Q^{N I I}}{A Q^{N I I} 1} \times\left[\left(1+r_{N I I}\right)^{\frac{N 1}{365}}-1\right] \times\left(1+r_{N I I}\right)^{\frac{N 2+n-1}{365}}+\left(1+r_{N I I}\right)^{\frac{N 2+n}{365}} \\
+\frac{R Q^{N I I}}{A Q^{N I 1}} \times I C_{N I I}^{u} \times\left(1+r_{N I I}\right)^{\frac{N 1+N 2+n-1}{365}}
\end{array}\right] \\
& \frac{d M P_{n}^{N I I 1}}{d D^{N}}=\frac{-F V}{\left(1-T C_{N I I}^{u}\right)} \times\left[\begin{array}{l}
\frac{R Q^{N I I}}{A Q^{N I I} 1} \times\left[\left(1+r_{N I I}\right)^{\frac{N 1}{365}}-1\right] \times\left(1+r_{N I I}\right)^{\frac{N 2+n-1}{365}}+\left(1+r_{N I I}\right)^{\frac{N 2+n}{365}} \\
+\frac{R Q^{N I I}}{A Q^{N I I}} \times I C_{N I I}^{u} \times\left(1+r_{N I I}\right)^{\frac{N 1+N 2+n-1}{365}}
\end{array}\right. \\
& \frac{O P P_{n}^{N I I} 1}{d R Q^{N I I}}=\frac{O P}{\left(1-T C_{N I I}^{u}\right) \times A Q^{N I I}} \times\left[\begin{array}{l}
\left.\left(1+r_{N I I}\right)^{\frac{N 1}{365}}-1\right] \times\left(1+r_{N I I}\right)^{\frac{N 2+n-1}{365}} \\
+I C_{N I I}^{u} \times\left(1+r_{N I I}\right)^{\frac{N 1+N 2+n-1}{365}}
\end{array}\right] \\
& \frac{O P P_{n}^{N I I 1}}{d A Q^{N I I 1}}=-\frac{R Q^{N I I}}{\left(1-T C_{N I I}^{u}\right) \times\left(A Q^{N I I}\right)^{2}} \times\left[\begin{array}{l}
{\left[\left(1+r_{N I I}\right)^{\frac{N 1}{365}}-1\right] \times\left(1+r_{N I I}\right)^{\frac{N 2+n-1}{365}}} \\
+I C_{N I I}^{u} \times\left(1+r_{N I I}\right)^{\frac{N 1+N 2+n-1}{365}}
\end{array}\right] \\
& \frac{O P P_{n}^{N I I 1}}{d O S^{N I}}=-\frac{O Q^{N I I} \times N N I I}{\left(1-T C_{N I I}^{u}\right) \times\left(O S^{N I}\right)^{2}} \times\left[\begin{array}{l}
\left.\left.\left[1+r_{N I I}\right)^{\frac{N 1}{365}}-1\right] \times\left(1+r_{N I I}\right)^{\frac{N 2+n-1}{365}}\right] \\
+I C_{N I I}^{u} \times\left(1+r_{N I I}\right)^{\frac{N 1+N 2+n-1}{365}}
\end{array}\right]
\end{aligned}
$$




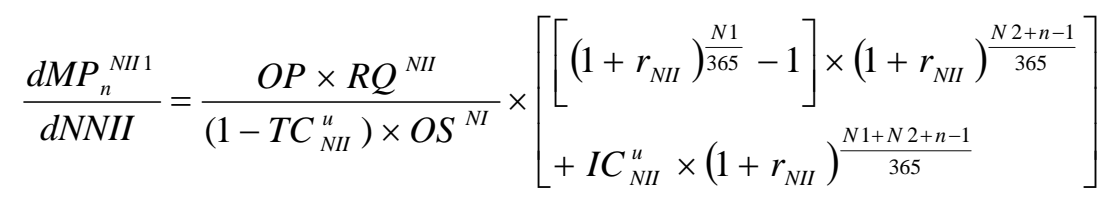

$\frac{d M P_{n}^{N I I 1}}{d r_{N I I}}=\frac{O P}{\left(1-T C_{N I I}^{u}\right)} \times\left[\begin{array}{l}\frac{R Q^{N I I}}{A Q^{N I I 1}} \times\left(1+r_{N I I}\right)^{\frac{N 2+n-1}{365}-1} \times\left[\begin{array}{l}\frac{N 1+N 2+n-1}{365} \times\left(1+r_{N I I} \frac{N 1}{365}-\frac{N 2+n-1}{365}+\right. \\ I C_{N I I}^{u} \times \frac{N 1+N 2+n-1}{365} \\ +\frac{N 2+n}{365} \times\left(1+r_{N I I}\right)^{\frac{N 2+n}{365}-1}\end{array}\right]\end{array}\right]$

$\frac{d M P_{n}^{N I I 1}}{d N 1}=\frac{O P \times R Q^{N I I} \times \operatorname{Ln}\left(1+r_{N I}\right) \times\left(1+I C_{N I I}^{u}\right) \times\left(1+r_{N I I}\right)^{\frac{N 1+N 2+n-1}{365}}}{\left(1-T C_{N I I}^{u}\right) \times A Q^{N I I} \times 365}$

$\frac{d M P_{n}^{N I 1}}{d N 2}=\frac{O P \times L n\left(1+r_{N I I}\right) \times\left(1+r_{N I I}\right)^{\frac{N 2}{365}}}{\left(1-T C_{N I I}^{u}\right) \times 365} \times\left[\begin{array}{l}\frac{R Q^{N I I}}{A Q^{N I 1}} \times\left[\left(1+r_{N I I}\right)^{\frac{N 1}{365}}-1\right] \times\left(1+r_{N I I}\right)^{\frac{n-1}{365}}+\left(1+r_{N I I}\right)^{\frac{n}{365}} \\ +\frac{R Q^{N I I}}{A Q^{N I 1}} \times I C_{N I I}^{u} \times\left(1+r_{N I I}\right)^{\frac{N 1+n-1}{365}}\end{array}\right]$

$\frac{d M P_{n}^{N I I 1}}{d n}=\frac{O P \times L n\left(1+r_{N I}\right) \times\left(1+r_{N I}\right)^{\frac{n}{365}}}{\left(1-T C_{N I I}^{u}\right) \times 365} \times\left[\begin{array}{l}\frac{R Q^{N I I}}{A Q^{N I 11}} \times\left[\left(1+r_{N I I}\right)^{\frac{N 1}{665}}-1\right] \times\left(1+r_{N I I}\right)^{\frac{N 2-1}{365}}+\left(1+r_{N I I}\right)^{\frac{N 2}{365}} \\ +\frac{R Q^{N I I}}{A Q^{N I 1}} \times I C_{N I I}^{u} \times\left(1+r_{N I I}\right)^{\frac{N 1+N 2-1}{365}}\end{array}\right]$

$\frac{d M P_{n}^{N I I 1}}{d I C_{N I I}^{u}}=\frac{O P \times R Q^{N I I} \times\left(1+r_{N I I}\right)^{\frac{N 1+N 2+n-1}{365}}}{\left(1-T C_{N I I}^{u}\right) \times A Q^{N I I 1}}$

$\frac{d M P_{n}^{N I I 1}}{d T C_{N I I}^{u}}=\frac{O P}{\left(1-T C_{N I I}^{u}\right)^{2}} \times\left[\begin{array}{l}\frac{R Q^{N I I}}{A Q^{N I I}} \times\left[\left(1+r_{N I I}\right)^{\frac{N 1}{365}}-1\right] \times\left(1+r_{N I I}\right)^{\frac{N 2+n-1}{365}}+\left(1+r_{N I I}\right)^{\frac{N 2+n}{365}} \\ +\frac{R Q^{N I I}}{A Q^{N I 1}} \times I C_{N I I}^{u} \times\left(1+r_{N I I}\right)^{\frac{N 1+N 2+n-1}{365}}\end{array}\right]$

\section{Appendix 2}

The determinants of the minimum price required by an institutional investor

$$
\begin{aligned}
& \frac{d M P_{n}^{I I 1}}{d O P}=\frac{1}{\left(1-T C_{I I}^{u}\right)} \times\left[\begin{array}{l}
S R^{I I 1} \times\left[\left(1+r_{I I}\right)^{\frac{N 1}{365}}-1\right] \times\left(1+r_{I I}\right)^{\frac{N 2+n-1}{365}}+\left(1+r_{I I}\right)^{\frac{N 2+n}{365}} \\
+S R^{I I 1} \times I C_{I I}^{u} \times\left(1+r_{I I}\right)^{\frac{N 1+N 2+n-1}{365}}
\end{array}\right] \\
& \frac{d M P_{n}^{I I 1}}{d D}=\frac{-F V}{\left(1-T C_{I I}^{u}\right)} \times\left[\begin{array}{l}
S R^{I I 1} \times\left[\left(1+r_{I I}\right)^{\frac{N 1}{365}}-1\right] \times\left(1+r_{I I}\right)^{\frac{N 2+n-1}{365}}+\left(1+r_{I I}\right)^{\frac{N 2+n}{365}} \\
+S R^{I I 1} \times I C_{I I}^{u} \times\left(1+r_{I I}\right)^{\frac{N 1+N 2+n-1}{365}}
\end{array}\right] \\
& \frac{d M P_{n}^{I I 1}}{d S R^{I I 1}}=\frac{O P}{\left(1-T C_{I I}^{u}\right)} \times\left[\left[\left(1+r_{I I}\right)^{\frac{N 1}{365}}-1\right] \times\left(1+r_{I I}\right)^{\frac{N 2+n-1}{365}}+I C_{I I}^{u} \times\left(1+r_{I I}\right)^{\frac{N 1+N 2+n-1}{365}}\right] \\
& \frac{d M P_{n}^{I I 1}}{d r_{I I}}=\frac{O P}{\left(1-T C_{I I}^{u}\right)} \times\left[\begin{array}{l}
\left(\frac{N 1+N 2+n-1}{365} \times\left(1+I C_{I I}^{u}\right) \times\left(1+r_{I I}\right)^{\frac{N 1}{365}}-\frac{N 2+n-1}{365}\right) \\
\times S R^{I I 1} \times\left(1+r_{I I}\right)^{\frac{N 2+n-1}{365}-1}+\frac{N 2+n}{365} \times\left(1+r_{I I}\right)^{\frac{N 2+n}{365}-1}
\end{array}\right] \\
& \frac{d M P_{n}^{I I 1}}{d N 1}=\frac{O P \times S R^{I I 1} \times L n\left(1+r_{I I}\right) \times\left(1+I C_{I I}^{u}\right) \times\left(1+r_{I I}\right)^{\frac{N 1+N 2+n-1}{365}}}{\left(1-T C_{I I}^{u}\right) \times 365}
\end{aligned}
$$




$$
\begin{aligned}
& O P \times\left[S R^{I I 1} \times\left[\left(1+r_{I I}\right)^{\frac{N 1}{365}}-1\right] \times\left(1+r_{I I}\right)^{\frac{n-1}{365}}+\left(1+r_{I I}\right)^{\frac{n}{365}}+S R^{I I 1} \times I C_{I I}^{u} \times\left(1+r_{I I}\right)^{\frac{N 1+n-1}{365}}\right] \\
& \frac{d M P_{n}^{I I 1}}{d N 2}=\frac{\times \operatorname{Ln}\left(1+r_{I I}\right) \times\left(1+r_{I I}\right)^{\frac{N 2}{365}}}{\left(1-T C_{I I}^{u}\right) \times 365} \\
& O P \times\left[S R^{I I 1} \times\left[\left(1+r_{I I}\right)^{\frac{N 1}{365}}-1\right] \times\left(1+r_{I I}\right)^{\frac{N 2-1}{365}}+\left(1+r_{I I}\right)^{\frac{N 2}{365}}+S R^{I I 1} \times I C_{I I}^{u} \times\left(1+r_{I I}\right)^{\frac{N 1+N 2-1}{365}}\right] \\
& \begin{array}{l}
\frac{d M P_{n}^{I I 1}}{d n}=\frac{\times \operatorname{Ln}\left(1+r_{I I}\right) \times\left(1+r_{I I}\right)^{\frac{n}{365}}}{(1-T C)} \\
\frac{d M P_{n}^{I I 1}}{d I C_{I I}^{u}}=\frac{O P \times S R^{I I 1} \times\left(1+r_{I I}\right)^{\frac{N 1+N 2+n-1}{365}}}{\left(1-T C_{I I}^{u}\right)}
\end{array} \\
& \frac{d M P_{n}^{I I 1}}{d T C_{I I}^{u}}=\frac{O P}{\left(1-T C_{I I}^{u}\right)^{2}} \times\left[\begin{array}{l}
S R^{I I 1} \times\left[\left(1+r_{I I}\right)^{\frac{N 1}{365}}-1\right] \times\left(1+r_{I I}\right)^{\frac{N 2+n-1}{365}}+\left(1+r_{I I}\right)^{\frac{N 2+n}{365}} \\
+S R^{I I 1} \times I C_{I I}^{u} \times\left(1+r_{I I}\right)^{\frac{N 1+N 2+n-1}{365}}
\end{array}\right]
\end{aligned}
$$

\section{References}

Agathee, U.S., Brooks, C., \& Sannassee, R.V. (2012). Hot and cold IPO markets: The case of the Stock Exchange of Mauritius. Journal of Multinational Financial Management, 22(4), 168-192.

Aggarwal, S., Liu, C., \& Rhee, R. (2008). Investor demand for IPOs and aftermarket performance: Evidence from the Hong Kong stock market. Journal of International Financial Markets, Institutions and Money, 18(2), 176-190.

Ahmad-Zaluki, N.A., Campbell, K., \& Goodacre, A. (2011). Earnings management in Malaysian IPOs: The East Asian crisis, ownership control, and post-IPO performance. The International Journal of Accounting, 46(2), 111-137.

Allen, F., \& Faulhaber, G.R. (1989). Signaling by underpricing in the IPO market. Journal of Financial Economics, 23(2), 303-323.

Amihud, Y., Hauser, S., \& Kirsh, A. (2003). Allocations, adverse selection, and cascades in IPOs: evidence from the Tel Aviv Stock Exchange. Journal of Financial Economics, 68(1), 137-158.

Arthurs, D.J., Busenitz, L.W, \& Hoskisson, R.E., Johnson, R.A. (2009). Signaling and initial public offerings: The use and impact of the lockup period. Journal of Business Venturing, 24(4), 360 372.

Ben Slama, S., \& Boudriga, A., Boulila, N. (2011). Determinants of IPO underpricing: Evidence from Tunisia. The International Journal of Business and Finance Research, 5(1), 13-32.

Beatty, R., \& Ritter, J.R. (1986). Investment banking, reputation, and the underpricing of initial public offerings. Journal of Financial Economics, 15(1), 213-232.

Berger, D., \& Turtle, H.J. (2012). Cross-sectional performance and investor sentiment in a multiple risk factor model. Journal of Banking and Finance, 36(4), 1107-1121

Brennan, J., \& Franks, J. (1997). Underpricing, ownership and control in initial public offerings of equity securities in the UK. Journal of Financial Economics, 45(3), 391-413.

Bubna, A., \& Prabhala, N.R. (2011). IPOs with and without allocation discretion: Empirical evidence. Journal of Financial Intermediation, 20(4), 530-561.

Cheng, L.T.W., Chan, K.C., \& Mak, B.S.C. (2005). Strategic share allocation and underpricings of IPOs in Hong Kong. International Business Review, 14(1), 41-59.

Chowdhry, B., \& Sherman, A. (1996). International differences in oversubscription and underpricing of IPOs. Journal of Corporate Finance, 2(4), 359-381.

Degeorge, F., Derrien, F., \& Womac, K.L. (2010). Auctioned IPOs: The US evidence. Journal of Financial Economics, 98 (2), 177-194. 
Gana, M.R., \& El Ammari, A. (2008). Initial underpricing and transfer of shares on the Tunisian stock exchange. Journal of Corporate Ownership and Control, 5(3), 434-444.

How, J., \& Yeo, J. (2000). The pricing of underwriting services in the Australian capital market. Pacific-Basin Finance Journal, 8(3-4), 347-373.

Ibbotson, R. (1975). Price performance of common stock new issues. Journal of Financial Economics, 2(3), 235-272.

Jiang, L., \& Li, G. (2013). Investor sentiment and IPO pricing during pre-market and aftermarket periods: Evidence from Hong Kong. Pacific-Basin Finance Journal, 23 (3), 65-82.

Jeribi, A., \& Jarboui, A. (2014). Explaining deliberate IPO price discount: Evidence from the Tunisian stock market. International Journal of Business and Emerging Markets, 6(2), 121-138.

Jeribi, A., Jeribi, Masmoudi .M., \& Jarboui, A. (2014). Voluntary and Involuntary Underpricing in IPOs. Global Business and Management Research: An International Journal, 6(2), 122-138.

Kanoun, S., \& Taktak, S. (2013). Information asymmetries, issuers' incentives and underpricing in emerging market: Some evidence from Tunisian IPO firms. International Journal of Economics, Commerce and Research, 3(5), 83-94.

Keloharju, M. (1993). The winner's curse, legal liability, and the long-run price performance of initial public offerings in Finland. Journal of Financial Economics, 34(2), 251-277.

Koh, F., \& Walter, T. (1989). A direct test of Rock's model of the pricing of unseasoned issues, Journal of Financial Economics, 23(2), 251-272.

Lee, P.J., Taylor, S.L., \& Walter, T.S. (1996). Expected and realized returns for Singaporean IPOs: initial and long-run analysis. Pacific-Basin Finance, 4(2), 153-180.

Levis, M. (1990). The winner's curse problem, interest costs and the underpricing of initial public offerings. Economic Journal, 100(399), 76-89.

Low, S.W., \& Yong, O. (2011). Explaining over-subscription in fixed-price IPOs : Evidence from the Malaysian stock market. Emerging Markets Review, 12(3), 205-216.

Marisetty, V.B., \& Subrahmanyam M.G. (2010). Journal of Financial Markets, 13(1), 196-223.

Michaely, R., \& Shaw, W. (1994). The pricing of initial public offerings: tests of adverse-selection and signaling theories. Review of Financial Studies, 7(2), 279-319.

Mok, H., \& Hui, Y. (1998). Under-pricing and aftermarket performance of IPOs in Shanghai, China. Pacific-Basin Finance Journal, 6 (5), 453-474.

Neupane, S., \& Poshakwale, S. (2012). Transparency in IPO mechanism: retail investors' participation, IPO pricing and returns. Journal of Banking and Finance, 36(7), 2064-2076.

Rock, K. (1986). Why new issues are underpriced. Journal of Financial Economics, 15 (1-2), 187212.

Roosenboom, P. (2012).Valuing and pricing IPOs. Journal of finance and Banking, 36(6), 16531664.

Sherman, A.E., \& Titman, S. (2002). Building the IPO order book : Underpricing and participation limits with costly information. Journal of Financial Economics, 65(1), 3-29.

Smith, C., (1986). Investment Banking and the Capital Acquisition Process. Journal of Financial Economics, 15(1), 3-29.

Welch, I., (1989). Seasoned offerings, imitation costs, and the underpricing of initial public offerings. Journal of Finance, 44(2), 421- 448.

Zheng, S.X., \& Li, M. (2008). Underpricing, ownership dispersion, and aftermarket liquidity of IPO stocks. Journal of Empirical Finance, 15(3), 436-454. 